Subscriber access provided by King Abdullah University of Science and Technology Library

\title{
Sustainability Engineering and Green Chemistry
}

\section{A Hybrid Hydrogel with High Water Vapor Harvesting Capacity for Deployable Solar-Driven Atmospheric Water Generator}

\author{
Renyuan Li, Yusuf Shi, Mossab Alsaedi, Mengchun Wu, Le Shi, and Peng Wang
}

Environ. Sci. Technol., Just Accepted Manuscript • DOI: 10.1021/acs.est.8b02852 • Publication Date (Web): 07 Sep 2018

Downloaded from http://pubs.acs.org on September 11, 2018

\section{Just Accepted}

"Just Accepted" manuscripts have been peer-reviewed and accepted for publication. They are posted online prior to technical editing, formatting for publication and author proofing. The American Chemical Society provides "Just Accepted" as a service to the research community to expedite the dissemination of scientific material as soon as possible after acceptance. "Just Accepted" manuscripts appear in full in PDF format accompanied by an HTML abstract. "Just Accepted" manuscripts have been fully peer reviewed, but should not be considered the official version of record. They are citable by the Digital Object Identifier (DOI®). "Just Accepted" is an optional service offered to authors. Therefore, the "Just Accepted" Web site may not include all articles that will be published in the journal. After a manuscript is technically edited and formatted, it will be removed from the "Just Accepted" Web site and published as an ASAP article. Note that technical editing may introduce minor changes to the manuscript text and/or graphics which could affect content, and all legal disclaimers and ethical guidelines that apply to the journal pertain. ACS cannot be held responsible for errors or consequences arising from the use of information contained in these "Just Accepted" manuscripts. 


\title{
1 A Hybrid Hydrogel with High Water Vapor
}

\section{Harvesting Capacity for Deployable Solar-Driven}

\section{Atmospheric Water Generator}

\author{
Renyuan Li, Yusuf Shi, Mossab Alsaedi, Mengchun Wu, Le Shi, and Peng Wang*
} (1)

Water Desalination and Reuse Center, Division of Biological and Environmental Science and Engineering, King Abdullah University of Science and Technology, Thuwal, 23955-6900, Saudi Arabia.

*Address correspondence to peng.wang@kaust.edu.sa

\section{Abstract}

The Earth's atmosphere holds approximately 12,900 billion tons of fresh water and it distributes all over the world with fast replenishment. The atmospheric water harvesting is emerging as a promising strategy for clean water production in arid regions, land-locked, and remote communities. The water vapor sorbent is the key component for atmospheric water harvesting devices based on absorbing-releasing process. In this work, a flexible hybrid photothermal water sorbent composed of deliquescent salt and hydrogel was rationally fabricated. It possesses superior water sorption capacity even in low humidity air thanks to the deliquescent salt and it maintains a solid form after it sorbs a large amount of water owing to the hydrogel platform. The harvested water could be easily released under regular sunlight via the photothermal effect, and it can be directly reused without noticeable capacity fading. An "easy-to-assemble-at-household" prototype device with $35 \mathrm{~g}$ of the dry hydrogel was tested outdoors in field conditions and delivered $20 \mathrm{~g}$ of fresh water within $2.5 \mathrm{~h}$ under natural sunlight. It is estimated that the material 
24 cost of making such a device to supply minimum daily water consumption for an adult (i.e., $3 \mathrm{~kg}$ )

25 is only \$3.2 (USD). This type of atmospheric water generator (AWG) is cheap and affordable,

26 perfectly works with a broad range of humidity, does not need any electricity, and thus is suitable

27 especially for clean water production in remote areas.

28 Keywords: atmospheric water harvesting, hydrogel, deliquescent salt, sunlight, potable water

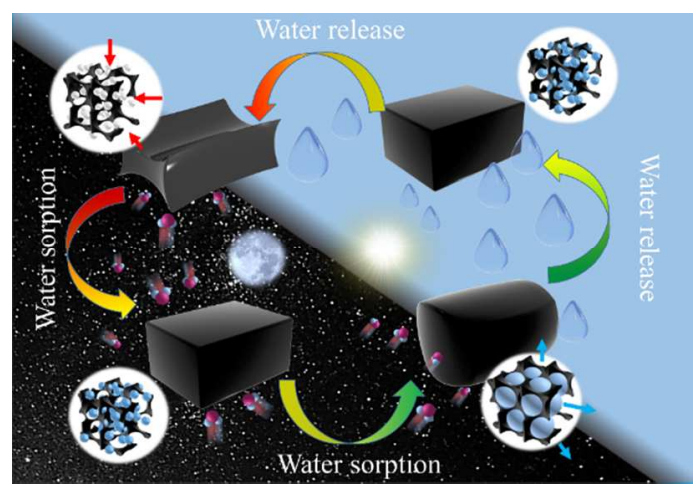

TOC Art

\section{Introduction}

34 Water scarcity is one of the most challenging issues that threaten the lives of mankind.

35 According to the report published by United Nations (UN) and World Health Organization

36 (WHO), water collection is a major burden in many countries especially in sub-Saharan Africa

37 where women and children take hours every day to collect drinking water due to the lack of basic

38 drinking water services nearby. ${ }^{1,2}$ On the other hand, the atmosphere preserves 12,900 billion

39 tons of fresh water, equivalent to $\sim 10 \%$ of water in all of the lakes on Earth. ${ }^{3}$ In light of rapid

40 population growth, widespread clean water shortage and water resource contamination,

41 harvesting atmospheric water to produce fresh water is emerging as an alternative and promising

42 approach especially for arid and landlocked regions. ${ }^{1,2,4-6}$ 
43 There are several ways of collecting air water, for example, fog harvesting, active refrigeration

44 and sorption in conjunction with easily accessible low grade energy. Fog harvesting is the most 45 ancient way, which directly collects the water droplets floating in the air. ${ }^{7-10}$ However, it is only 46 viable in very limited areas because constantly high ambient relative humidity (RH) $(\sim 100 \%)$ is

47 the necessity for this technology. ${ }^{11-13}$ The refrigeration method, which has been widely

48 investigated, involves using an engineered cold surface to cool adjacent air mass below the dew 49 point to produce water droplet via condensation. ${ }^{14-15}$ It is believed that the refrigeration is 50 infeasible for regions with consistently low $\mathrm{RH}(<40 \%)$ or those lack of electricity. ${ }^{16}$ On the 51 other hand, the sorption based method employs water sorbent to sorb water vapor from air, 52 followed by heating up the saturated sorbent to release and subsequently condense the water. ${ }^{17-18}$ 53 The most attractive advantage of this sorption based method is its capability of producing water 54 from dry air with humidity even lower than $20 \%$ in the absence of electricity. ${ }^{19}$ Particularly, 55 solar-thermal process along with effective water vapor sorbent has recently delivered all-in-one, 56 fully solar energy driven, and thus autonomous atmospheric water generator (AWG) devices. ${ }^{16 \text {, }}$

$57 \quad{ }^{19-20}$ In these devices, the key to their successful performances is the selection of water vapor 58 sorbent which should be capable of sorbing large amount of water even from air with reasonably 59 low humidity and releasing water at a relatively low temperature $\left(70-90{ }^{\circ} \mathrm{C}\right)$ that can be achieved 60 by photothermal materials under regular or even weakened sunlight intensity. ${ }^{21-24}$

61 Conventional desiccants, such as silica gel, zeolite, activated alumina, typically have wide water 62 vapor sorption window. However, these desiccants are mainly based on physical adsorption and 63 the energy required to release the adsorbed water is proportional to the water-desiccant affinity. 64 In other words, for these desiccants, the easier water vapor is adsorbed, the higher temperature it 65 is needed to release water. Thus, to efficiently release the captured water, they require high 
66 temperatures $\left(>160{ }^{\circ} \mathrm{C}\right)$, which are typically beyond what simple solar photothermal based

67 heating devices are capable of offering. ${ }^{25-28}$ In 2017 and 2018, it was demonstrated in lab and

68 field conditions that certain metal-organic-frameworks (MOFs), due to their outstanding sorption

69 ability with water vapor, delivered potable water from dry air (RH 10-40\%) under regular solar

70 irradiation conditions. ${ }^{16,19}$ Anhydrate salt based water sorbents have also been recently reported

71 for AWG application, which works well under low RH (i.e. 10\%-35\%) and are able to deliver

72 about $20 \%$ liquid water of their own weight. ${ }^{20}$

73 Deliquescent salt has a high affinity with water and is able to sorb water vapor as many as 5-6

74 times its own weight, which is significantly higher than most porous sorbents. ${ }^{29-30}$ As a matter of

75 fact, deliquescent salt is so effective in capturing water vapor that the captured water vapor

76 ultimately dissolves the salt and forms an aqueous solution with a much expanded volume. In a

77 sense, deliquescence property of the salt would break the physical confinement constraint in

78 terms of the amount of water vapor captured by the conventional porous desiccants where the

79 pore volumes of the solid materials set the upper limits. However, the liquid form causes troubles

80 in handling and engineering design for applying deliquescent salts to water sorption. Recently,

81 Gido et al theoretically proposed an atmospheric water harvesting system, which employs

82 lithium chloride solution as water vapor sorbent and can produce water in a continuous process.

83 Based on their simulations, the energy consumption can be reduced up to $65 \%$ comparing with

84 conventional condensation based system. ${ }^{31}$ In this work, we employ a cross-linked and flexible

85 hydrogel network to keep the deliquescent salt solution in place, and the easily expandable

86 hydrogel network provides a perfectly supporting platform which shows no constraint on the

87 water sorption performance by the salt while maintains the salt solution in a solid form. 
A proof-of-concept is provided by using $\mathrm{CaCl}_{2}$, a cheap, stable, eco-friendly, and nontoxic deliquescent salt. The hydration reaction of $\mathrm{CaCl}_{2}$ enables it to capture water at low humidity (i.e. RH $10-25 \%$ ) while its deliquescence further draws more water vapor into the dissolving salt with $\mathrm{RH}$ ranges down to $26 \%$ at $25^{\circ} \mathrm{C}$, making it an effective water sorbent for wide range with a superior capacity. With a solar photothermal component built in, the deliquescent-salt-hydrogelphotothermal composite material in this work captures $0.74,1.10$, and $1.75 \mathrm{~g}$ of water vapor for each gram of the dry composite material under $\mathrm{RH}$ of 35,60 and $80 \%$, respectively (mixing ratio $6.5,11.8$ and $16.2 \mathrm{~g} / \mathrm{kg}_{\text {air }}$ ), and it releases almost $100 \%$ of the captured water under irradiation with regular sunlight intensity. The water capture capacity achieved at $35 \%$ humidity is three times higher than the MOF and $\mathrm{CuCl}_{2}$ materials. In field condition outdoors (April 2018 at Thuwal, Saudi Arabia), an "easy-to-assemble at household" and all-in-one prototype device with a dry hydrogel disk of $35 \mathrm{~g}$ in it sorbed $37 \mathrm{~g}$ of water vapor from an open air with $\mathrm{RH}$ between $60-70 \%$. Under natural sunlight, the device quickly delivered $\sim 20 \mathrm{~g}$ of fresh water within just 2.5 hours. Based on these performances and by extrapolation, it is estimated that the material cost of the AWG device to supply a minimum daily water need (3 kg/day) for an adult is only $\$ 3.2$ USD. This technology provides a promising solution for clean water production in arid and land lockremote regions. The superior water harvesting capacity within wide RH range makes the composite hydrogel in this work a versatile AWG for islands regions and inland areas with low to high RH as well.

\section{Experiment and methods}

\section{Chemicals and materials}

Acrylamide monomer (AM, 99\%, Sigma-Aldrich), potassium persulfate (KPS, 99\%, Acros

Organics), N, N'-methylenebisacrylamide (MBAA, 99\%, Sigma-Aldrich), N,N,N',N'- 
111 tetramethylethylenediamine (TEMED, 99\%, Sigma-Aldrich), carbon nanotubes (CNTs), nitric

112 acid and calcium chloride $\left(\mathrm{CaCl}_{2}, 99 \%\right.$, Sigma-Aldrich) were used without further purification.

113 Deionized (DI) water (18.2 M $\Omega$, from Milli-Q system) was used throughout the experiments.

114 Multi-walled carbon nanotubes were purchased from Sigma-Aldrich.

\section{Material characterization}

116 Scanning electron microscope (SEM) images were captured on a FEI Nova Nano 630

117 microscope. The UV-vis-NIR absorption spectrum was conducted on an Agilent Cary 5000 UV118 vis-NIR spectrophotometer. X-ray diffraction (XRD) analysis was performed by a Bruker D8

119 Advance diffractometer $(\mathrm{Cu} \mathrm{K \alpha}$, the wave length is $1.5418 \AA)$. The contact angle was measured 120 with an OCA 35 (DataPhysics, Filderstadt, Germany) at ambient temperature using a $5 \mu \mathrm{L}$ water 121 droplet as the indicator. The mechanical stretching test was carried out on an INSTRON 5944

122 universal testing system. Inductively coupled plasma-optical emission spectroscopy (ICP-OES)

123 (Optima 8300, PerkinElmer, Inc.) was used to test the quality of final product.

\section{Fabrication of PAM-CNT-CaCl 2 hydrogel}

125

126

127

128

129

130

131

132
Pretreatment of CNT. An aliquot of $6.0 \mathrm{~g}$ of as purchased CNTs $(6-9 \mathrm{~nm} \times 5 \mu \mathrm{m})$ was dispersed in a mixture of $70 \%$ nitric acid $(60 \mathrm{~mL})$ and $97 \%$ sulfuric acid $(180 \mathrm{~mL})$. The dispersion was then refluxed for $4 \mathrm{~h}$ at $70{ }^{\circ} \mathrm{C}$ followed by $2 \mathrm{~h}$ sonication. The as-treated dispersion was filtrated and washed by DI water thoroughly before use.

PAM-CNT-CaCl 2 hydrogel. $1.0 \mathrm{~g}$ of AM was dissolved in $5 \mathrm{ml}$ of the CNT dispersion with a specified amount of CNT added (i.e. 2.500, 1.250, 0.500, 0.375, 0.250, 0.125, 0.050, 0.025 mg).

Then the AM-CNT dispersion was purged with nitrogen to eliminate dissolved oxygen. $5.00 \mathrm{mg}$ of KPS as initiator and $0.38 \mathrm{mg}$ of MBAA as crosslinking agent were then added into the AM- 
133 CNT dispersion. Finally $25 \mu \mathrm{L}$ of TEMED was added as the crosslinking accelerator. PAM-CNT 134 hydrogel was obtained after the mixture was settled overnight. To load $\mathrm{CaCl}_{2}$, the as-prepared 135 PAM-CNT hydrogel was freeze dried at $-80{ }^{\circ} \mathrm{C}$ (FreeZone 2.5 plus, LABCONCO) followed by 136 immersing it into $10 \mathrm{ml}$ of $\mathrm{CaCl}_{2}$ solution with varied concentration (i.e. $0.1,0.2,0.3,0.4,0.5$, 137 and $0.6 \mathrm{~g} / \mathrm{mL}$ ) for 24 hours under ambient condition (i.e. $\mathrm{RH} 60 \%, 22{ }^{\circ} \mathrm{C}$ ). The as-prepared 138 PAM-CNT-CaCl 2 hydrogel was dried at $80{ }^{\circ} \mathrm{C}$ in a blast oven for 3 days.

\section{Water sorption experiments}

140 Water vapor sorption tests were conducted on a NETZSCH Jupiter ${ }^{\circledR}$ simultaneous thermal 141 analyzer (STA) 449 measurement system coupled with water vapor generator. For the dynamic $142 \mathrm{RH}$ test, the water vapor generator was programmed to output nitrogen flow with different $\mathrm{RH}$ 143 along with variable equilibration time. The STA furnace was first heated up to $80{ }^{\circ} \mathrm{C}$ and 144 maintained for 2 hours with a constant RH of $1.5 \%$ to release sorbed water. After dehydration 145 process, the STA furnace was then cooled down to $25^{\circ} \mathrm{C}$ for water vapor sorption test. During 146 the water vapor sorption test, the RH was programmed to increase step by step from 5\% to $30 \%$ 147 with a step interval of 5\% and equilibration time for each step of $60 \mathrm{~min}$. For the RH range 148 between $30 \%$ and $80 \%$, the step interval was $10 \%$ with an equilibration time of $60 \mathrm{~min}$ for each 149 step. For the static RH test, the water vapor generator was programmed to output nitrogen flow 150 with static RH and a constant equilibration time of 1000 min was employed.

151 Solar photothermal assisted water release, and device fabrication and their performance 152 measurement outdoors

153 The as-prepared PAM-CNT- $\mathrm{CaCl}_{2}$ hydrogel was first exposed to $60 \% \mathrm{RH}$ atmosphere for $36 \mathrm{~h}$ at 154 room temperature $\left(22^{\circ} \mathrm{C}\right)$ to reach its water saturation. The water-saturated PAM-CNT-CaCl 2 
155 hydrogel was then directly exposed to simulated sunlight (Oriel solar simulator) at certain light 156 intensity (i.e. $1.0,0.8,0.6 \mathrm{~kW} / \mathrm{m}^{2}$ ). The weight change of the hydrogel was monitored and 157 recorded, and the temperature of the hydrogel top surface was measured by IR camera. To test 158 the stability of PAM-CNT- $\mathrm{CaCl}_{2}$ hydrogel, the water sorption/release experiments were 159 conducted under $1 \mathrm{~kW} / \mathrm{m}^{2}$ for 10 times.

160 An "easy-to-assemble-at-household" and all-in-one device was further fabricated for field 161 condition measurement. The very simple device used a disposable plastic lunch box as the 162 container, aluminum foil as isolator and copper foil as heat conductor. The lunch box cap was cut 163 open to have a hole of $10 \times 10 \mathrm{~cm}^{2}$ which was covered with a piece of anti-fogging glass to let 164 sunlight in. The device with a round-shaped hydrogel in it was first kept in an open air (RH 60$16570 \%$ ) for 17 hours without capping. Then the lunch box was capped. The device was let sit 166 outside during daytime for 2.5 hours (From 13:20-15:50) on April 29, 2018 at KAUST campus 167 and the liquid fresh water was collected. A magnifying glass was further combined with a 168 modified device and its water release performance was investigated. 


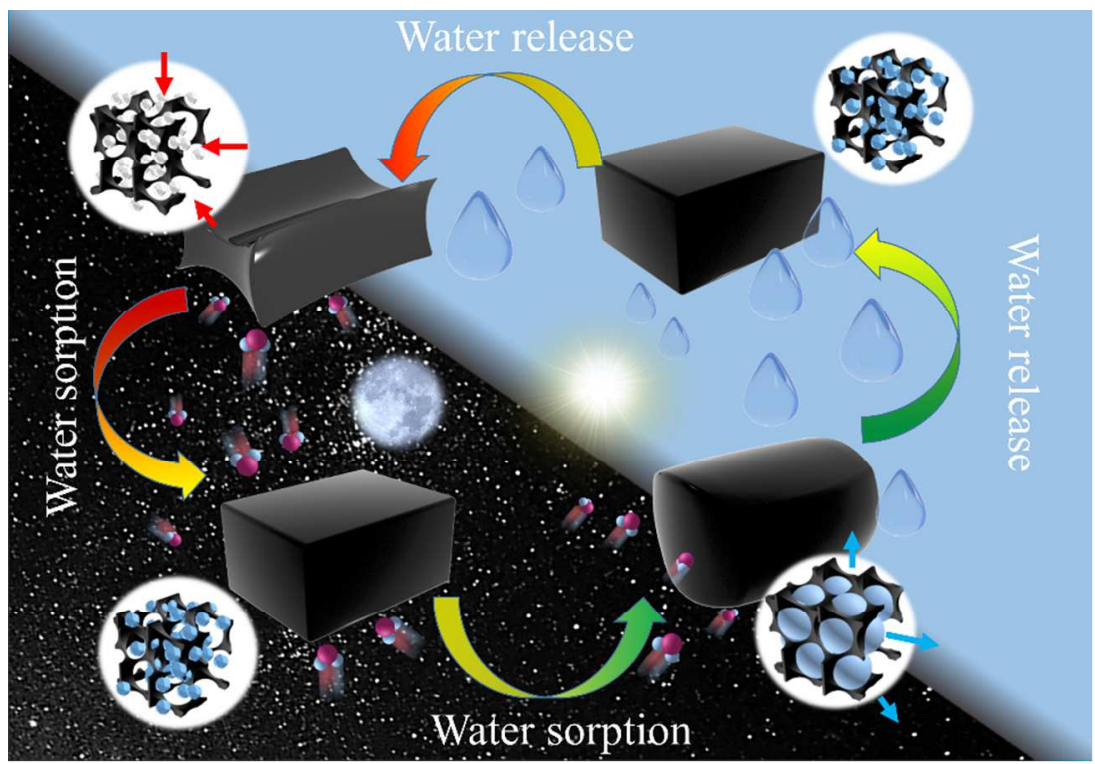

172 Figure 1: The conceptual design of the hybrid hydrogel as AWG. Water vapor can be captured

173 during night time and released during day time under assistance of sunlight. The flexible

174 property of hydrogel substrate ensures the unsuppressed water vapor sorption capacity.

175 In this work, we present a novel capacity-enhanced water vapor sorbent for AWG application.

176 The sorbent is in a form of hydrogel with deliquescent salt (i.e. $\mathrm{CaCl}_{2}$ in this work) imbedded

177 inside the hydrogel and the salt is responsible for atmospheric water vapor harvesting. The cross-

178 linked hydrogel network holds and keeps the deliquescent $\mathrm{CaCl}_{2}$ solution in a solid form, and the

179 flexible expansion behavior of the hydrogel makes the pore volume not a limiting factor and thus

180 enhances the water sorption capacities beyond conventional porous desiccants with rigid

181 frameworks. A simple but all-in-one AWG device is fabricated to demonstrate its working

182 principle and performance under field conditions: (a) the composite hydrogel sorbs water vapor

183 in open air at night when humidity is higher and temperature is lower; (b) water is released from

184 the hydrogel in an close chamber at a high temperature produced by the photothermal heating

185 effect at daytime by using sunlight as the only energy source; (c) air-cooling assisted water 
186 condensation (passive cooling condensation) and collection takes place in the same close

187 chamber inside the device (Figure 1).

\section{Synthesis of PAM-CNT-CaCl 2 hydrogel.}

189 PAM is selected as the hydrogel network in this work because of its chemical stability, water 190 retaining ability, flexibility and low cost. ${ }^{32-35} \mathrm{CNT}$ is used as the photothermal component due to 191 its chemical stability, superior light absorbance and outstanding light-to-heat conversion 192 efficiency as demonstrated in the literatures. ${ }^{36-37}$ In this project, polyacrylamide(PAM)-CNT 193 hydrogel was synthesized by in situ polymerization of Acrylamide(AM) monomer in the 194 presence of CNTs (step 1 and 2 in Figure 2). The as-made hydrogel was then made into 195 macroporous hydrogel by a freeze-drying process (step 3 in Figure 2). Finally, PAM-CNT-CaCl 2 196 hydrogel was fabricated by immersing the freeze-dried sample in the $\mathrm{CaCl}_{2}$ aqueous solution 197 (step 4 in Figure 2), followed by directly drying in a blast oven to removal water (step 5 in 198 Figure 2).

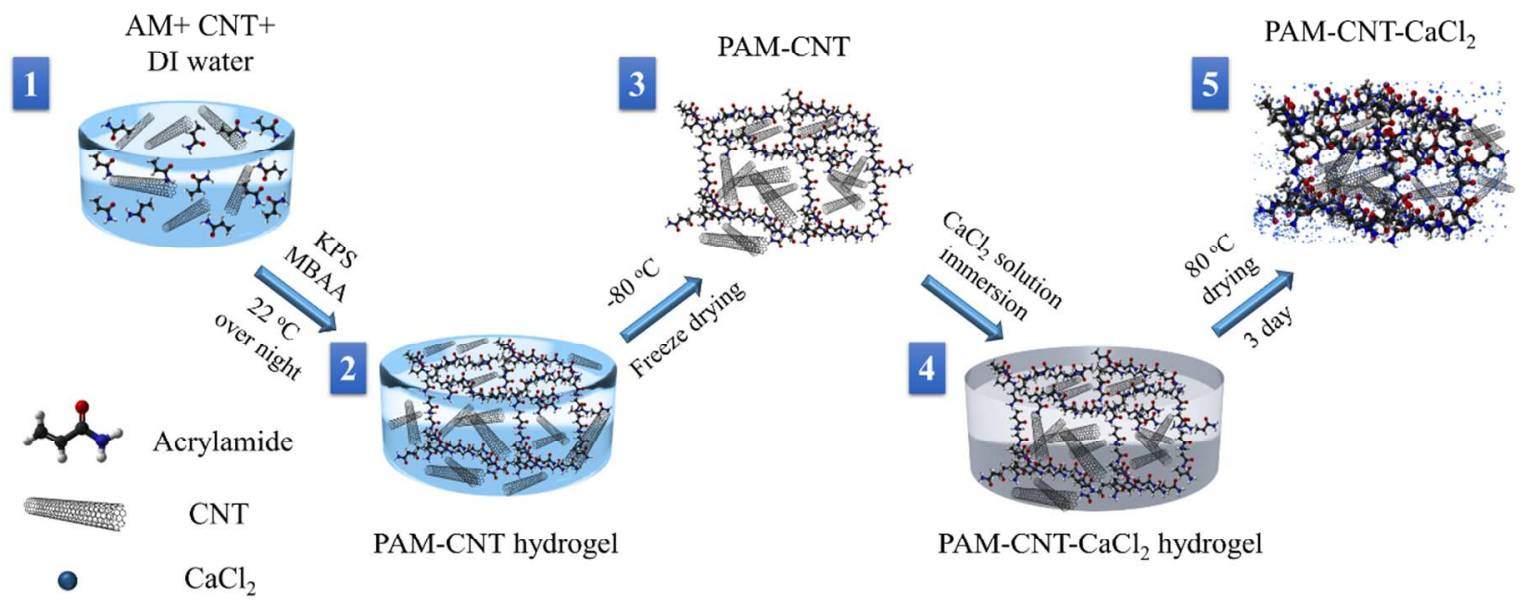

Figure 2. Schematic of PAM-CNT-CaCl 2 hydrogel synthesis process. 
201 The structure rigidity of the hydrogel is strongly dependent on the amount of the polymer in the

202 hydrogel, which can be modulated by changing the amount of AM monomer in the synthesis

203 process. ${ }^{38}$ The amount of the AM monomer precursor in the work is optimized to be $20 \mathrm{wt} \%$

204 (monomer to solvent ratio) based on the following facts and the cost consideration: (1) the AM

205 monomer of $20 \mathrm{wt} \%$ is the value at which the PAM hydrogel exhibits a standalone solid form

206 and has a sufficient structural stability. If the AM monomer concentration is lower than $20 \%$, the

207 product start to forms sticky and thick liquid-like structure; (2) increasing AM monomer

208 concentration to above $20 \mathrm{wt} \%$ does not lead to any noticeable benefit of enhanced water

209 sorption and release.
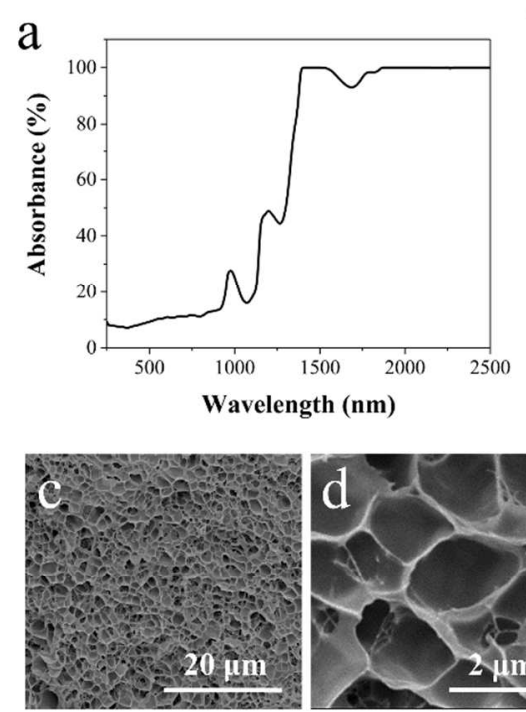

b
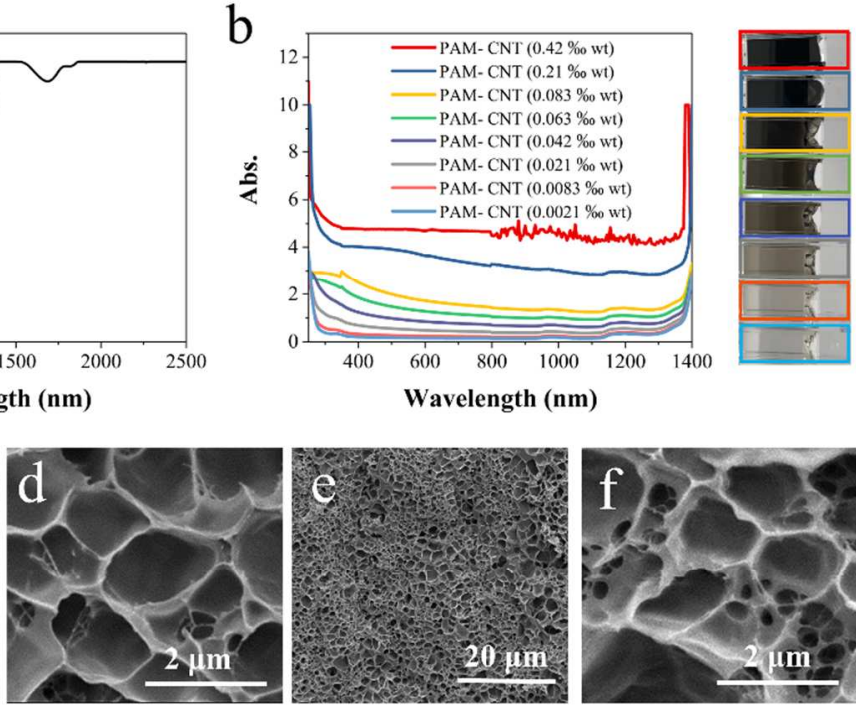

Figure 3. UV-vis-NIR absorption spectra of (a) water and (b) PAM-CNT hydrogels with varying amount of CNT loading. Inset photos are the image of PAM-CNT hydrogels with different CNT loading amount. SEM image of (c) and (d) PAM, (e) and (f) PAM-CNT.

214 UV-vis-NIR spectrum of water is shown in Figure 3 (a), indicating its strong absorption of NIR 215 light at wavelength above $1400 \mathrm{~nm} \cdot{ }^{39-40}$ The purpose of adding CNTs in the hydrogel is mainly to increase the light absorption from 240 to $1400 \mathrm{~nm}$. Figure 3 (b) compares the UV-vis-NIR 
217 absorption spectra between 240 and $1400 \mathrm{~nm}$ of PAM-CNT hydrogels with a fixed thickness of 5

218 mm but different CNT loading amounts. As seen, a small amount of CNT in the hydrogel (i.e.

219 ppm level) would lead to a large increase in light absorbance. ${ }^{41-42} 99 \%$ of the incident light was

220 absorbed when the CNT loading amount was only 0.083 wt\%o. In this work, the CNT loading in

221 the hydrogel was set to be $0.42 \mathrm{wt} \%$, where almost $100 \%$ of the incident light was absorbed.

222 Figures 2 (c) and (d) present the SEM images of the crosslinked hydrogel after freeze drying. As

223 seen, the freeze-dried PAM hydrogel shows porous structure with an averaged pore diameter

224 around $3 \mu \mathrm{m}$ (Figure 3 (c)) and wall thickness of $\sim 100 \mathrm{~nm}$ (Figure 3 (d)). With PAM-CNT, the

225 pore size was reduced to around $2 \mu \mathrm{m}$ (Figure 3 (e)) while the wall thickness remained

226 unchanged (Figure $3(\mathrm{f}))$.

$227 \mathrm{CaCl}_{2}$ was then loaded into PAM-CNT hydrogel by aqueous solution based impregnation. In

228 doing so, $5 \mathrm{~cm}^{3}$ of the freeze-dried PAM-CNT was immersed in $10 \mathrm{~mL}$ of $\mathrm{CaCl}_{2}$ aqueous

229 solution with different concentrations (i.e., $0.1,0.2,0.3,0.4,0.5$ and $0.6 \mathrm{~g} / \mathrm{mL}$ ) for 24 hours,

230 followed by drying to remove water. As seen in Figure S1, the volume of the hydrogels

231 expanded differently in response to the immersion in $\mathrm{CaCl}_{2}$ solutions with different

232 concentrations. At the end of 24 hours, for the hydrogels treated with low $\mathrm{CaCl}_{2}$ concentrations

$233(0.1,0.2,0.3$ and $0.4 \mathrm{mg} / \mathrm{mL})$, almost $100 \%$ of the solution was sorbed and retained inside the

234 hydrogels. In the case of the 0.5 and $0.6 \mathrm{~g} / \mathrm{mL} \mathrm{CaCl}_{2}$ solutions, only $62 \%$ and $50 \%$ of $\mathrm{CaCl}_{2}$ in

235 the solutions were incorporated into the hydrogel network, which is presumably due to the

236 reduced swelling ratio of $\mathrm{PAM}-\mathrm{CNT}-\mathrm{CaCl}_{2}$ hydrogel within highly concentrated $\mathrm{CaCl}_{2}$ solution.

237 First, it has been reported that the coordination between carbonyl $(\mathrm{C}=\mathrm{O})$ oxygens of PAM and

$238 \mathrm{Ca}^{2+}$ enhances the physical crosslinking of PAM chains. Secondly, the "salting-out" effect causes

239 the shrinkage of the PAM's hydrodynamic volume and overlap of the PAM chains. Both of these 
240 two effects decrease the swelling ratio of the hydrogel. This result is similar to that the solubility

241 of PAM in water decreases at a high concentration of salt as reported in the literatures. ${ }^{43-46}$ The

242 mass loading of $\mathrm{CaCl}_{2}$ in the hydrogels, which was estimated by the weight difference of the

243 dried samples before and after the salt loading, was 1.0, 2.0, 3.0, 4.0, 3.1 and $3.0 \mathrm{~g}$ for each gram

244 of the dry PAM-CNT for the $\mathrm{CaCl}_{2}$ solution concentrations of $0.1,0.2,0.3,0.4,0.5$ and $0.6 \mathrm{~g} / \mathrm{mL}$,

245 respectively. Clearly, the $\mathrm{CaCl}_{2}$ immersion solution with a concentration of $0.4 \mathrm{~g} / \mathrm{mL}$ gives the

246 highest $\mathrm{CaCl}_{2}$ loading among all.

247 To evaluate the water sorption capacity of the hydrogels with different $\mathrm{CaCl}_{2}$ loading amounts,

248 the as-prepared dry hydrogels were put under constant RH for 36 hours to reach their water

249 sorption saturation. Two constant RH conditions (35\% and 60\%) were tested and the results are

250 presented in Figure 4 (a). For both $\mathrm{RH}$ conditions, it is found that the $\mathrm{CaCl}_{2}$ mass loading of 4.0

$251 \mathrm{~g} / \mathrm{g}$, corresponding to the immersion $\mathrm{CaCl}_{2}$ solution of $0.4 \mathrm{~g} / \mathrm{mL}$ in the preparation, gave the

252 highest water vapor sorption capacity, among all samples tested. This result is as expected since

$253 \mathrm{CaCl}_{2}$ is the water sorbent in the hydrogel. Thus, PAM-CNT-CaCl 2 with the $\mathrm{CaCl}_{2}$ mass loading

254 of $4.0 \mathrm{~g} / \mathrm{g}$ is chosen as the optimized one for further investigation thereafter.

255 Figures 4 (b-1)-(b-3) show the photos of $\mathrm{CaCl}_{2}$ salt before and after its water vapor sorption. It

256 can be seen that the white solid salt was fully liquidized to a colorless transparent solution after

$257 \mathrm{CaCl}_{2}$ salt being exposed in $60 \% \mathrm{RH}$ air. Figures 3 (c-1)-(c-3) present the photos of PAM-CNT-

$258 \mathrm{CaCl}_{2}$ hydrogels before and after the same water sorption tests. After the water sorption, the

259 PAM-CNT-CaCl 2 hydrogel significantly expanded but still in a solid form like a soft rubber.

260 Mechanical property was also tested to evaluate the physical stability of the hydrogel (Figure S2).

261 As can be seen, the elastic deformation was as high as $1250 \%$ for $\mathrm{PAM}-\mathrm{CaCl}_{2}$ and $560 \%$ for 

and $35.1 \mathrm{kPa}$, respectively.

a

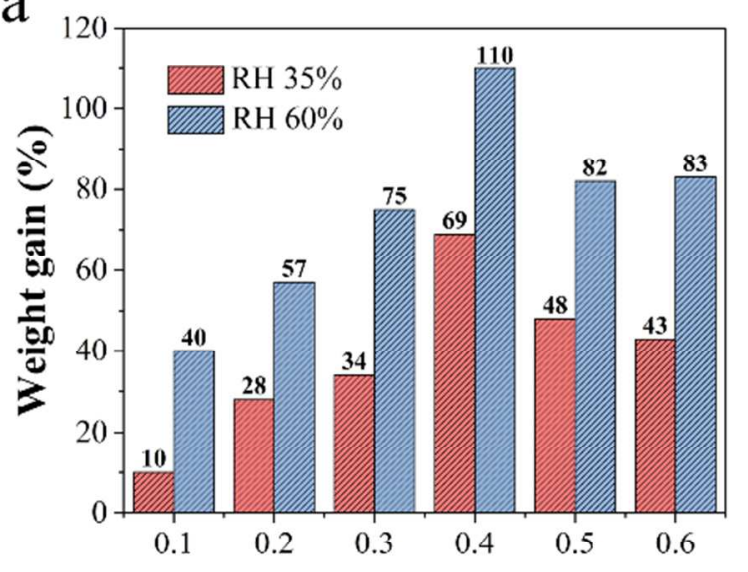

Concentration of $\mathrm{CaCl}_{2}$ solution $(\mathrm{g} / \mathrm{mL})$
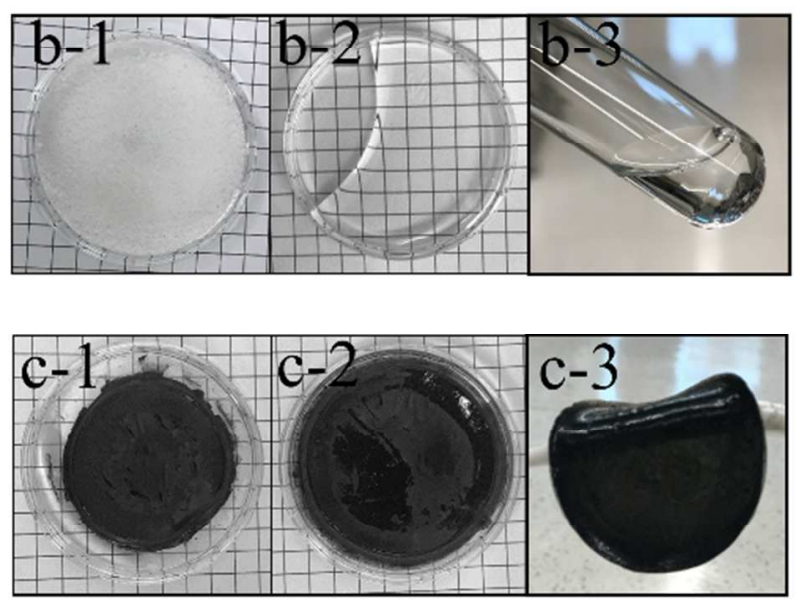

Figure 4. (a) Water saturation of $\mathrm{PAM}-\mathrm{CNT}-\mathrm{CaCl}_{2}$ hydrogel with varied $\mathrm{CaCl}_{2}$ loading at $\mathrm{RH} 35 \%$ and RH $60 \%$. Weight gain (\%) is relative to the dry weight before the sorption. Digital photos of $\mathrm{CaCl}_{2}$ (b-1) before and (b-2 and b-3) after water vapor sorption, PAM-CNT-CaCl 2 (c-1) before and (c-2 and c-3) after water vapor sorption. (c-3) shows the water-sorbed hydrogel being held by a plastic tube, indicates its flexible and stable property.

\section{Water sorption assessment}

The water sorption behaviors of the hydrogel were then investigated and compared in details under dynamic and static humidity scenario. A constant temperature of $25^{\circ} \mathrm{C}$ was set and kept throughout the water sorption process for all samples. The choice of $25^{\circ} \mathrm{C}$ was based on the fact that this temperature is a typical in arid areas at night when water vapor sorption takes place. All samples for water sorption assessment were first dried prior test. In the dynamic scenario, the hydrogels were kept in a flow with a step-wise increasing humidity for certain period of time while for the static scenario the RH was kept unchanged throughout the water sorption process. 
279 Details regarding to the STA programs are provided in the Materials and Methods section (water 280 sorption experiments).

281 The dynamic RH test was first applied to PAM and PAM-CNT hydrogels (Figure S3 a and c).

282 Both of them showed a similar water sorption characteristic, with the water vapor sorption 283 slightly higher for the dried PAM than the dried CNT-PAM in the low humidity range (RH $284<40 \%$, mixing ratio $<7.9 \mathrm{~g} / \mathrm{kg}_{\text {air }}$ ) and no obvious difference in high $\mathrm{RH}$ range. However, there 285 was no significant difference in high humidity range.

286 The static RH test result (Figure S3 b and d) indicates that PAM and PAM-CNT hydrogels 287 gradually approached water uptake value near to its saturation capacity within 400 min, and the 288 final weight change due to water sorption are $32 \mathrm{wt} \%$ and $38 \mathrm{wt} \%$ water in $80 \% \mathrm{RH}$, respectively.

289 As can be seen in Figure $5(\mathrm{~d})$ and $(\mathrm{g})$, both $\mathrm{PAM}-\mathrm{CaCl}_{2}$ and $\mathrm{PAM}-\mathrm{CNT}-\mathrm{CaCl}_{2}$ samples shared 290 similar RH-dependent water vapor sorption trend in dynamic water sorption measurement. The 291 water sorption both started at a very low humidity of 5\%, and then gradually increased with the 292 increase of humidity, with much higher water sorption amounts than the hydrogels without $\mathrm{CaCl}_{2}$ 293 loading under otherwise the same condition. The water sorption curves recorded in static $\mathrm{RH}$ 294 condition with different RH are presented in Figure 5 (e) and (h). With RH of 10, 35, 60 and $29580 \%$, the water sorption amounts at the end of the experiment were $6,72,116,203 \%$ for PAM$296 \mathrm{CaCl}_{2}$, and 5, 69, 110, 173\% for PAM-CNT-CaCl 2 sample, respectively. The amount of water 297 sorbed by PAM- $-\mathrm{CaCl}_{2}$ and PAM-CNT- $\mathrm{CaCl}_{2}$ at $80 \%$ humidity are 6.3 and 4.5 times the weight 298 of the respective hydrogels before loading with $\mathrm{CaCl}_{2}$ (Figure $\mathrm{S} 3 \mathrm{~b}$ and d) which clearly 299 demonstrates the effectiveness of $\mathrm{CaCl}_{2}$ in water sorption. 
300 The water sorption property of the hydrogels with $\mathrm{CaCl}_{2}$ loading is very similar to that of pure

$301 \mathrm{CaCl}_{2}$ crystal (Figure 5 (a) and (b)), with only slight difference in specific sorption amount, 302 indicating that $\mathrm{CaCl}_{2}$ is majorly responsible for the water sorption of the PAM-CNT-CaCl 2 .

303 Since the phase diagram of water- $\mathrm{CaCl}_{2}$ has been well studied and can be easily found in the 304 literature, we believe it can be used to explain the water sorption behavior of our PAM-CNT$305 \mathrm{CaCl}_{2}$ hydrogel. ${ }^{47}$ The $\mathrm{CaCl}_{2}$ contains two primary stage regarding to the water sorption process. 306 In the first stage, anhydrous $\mathrm{CaCl}_{2}$ crystal captures water molecules through hydration reaction 307 and forms hydrates. After the $\mathrm{CaCl}_{2}$ sorbs enough water and forms $\mathrm{CaCl}_{2} \cdot 6 \mathrm{H}_{2} \mathrm{O}$, it is then 308 dissolved in the sorbed water as more water is sorbed. The vapor pressure of a saturation $\mathrm{CaCl}_{2}$ 309 aqueous solution at $25{ }^{\circ} \mathrm{C}$ is $0.9 \mathrm{kPa}$, equivalent to a humidity of $26 \%$ (mixing ratio $4.9 \mathrm{~g} / \mathrm{kg}_{\text {air }}$ ).

310 In other words, the water sorption by $\mathrm{CaCl}_{2}$ at a $\mathrm{RH}<26 \%$ is attributed to its increase of the 311 hydration water, and that occurred at $\mathrm{RH}>26 \%$ leads to a dilution of $\mathrm{CaCl}_{2}$ aqueous solution, i.e. 312 deliquescence. It should be pointed out that the value of this $\mathrm{RH}$ of $26 \%$ as a critical point can be 313 varied with the ambient temperature.

314 Theoretically, the water sorption amount in the first stage for pure anhydrous $\mathrm{CaCl}_{2}$ is $97 \%$ 315 ending as $\mathrm{CaCl}_{2} \cdot 6 \mathrm{H}_{2} \mathrm{O}$. However, the last two hydrate molecules of water are hard to be removed 316 at a temperature lower than $160{ }^{\circ} \mathrm{C} .{ }^{48}$ In our case, the samples were pre-dried at $80{ }^{\circ} \mathrm{C}$ because 317 this is a reasonable temperature that can be achieved by photothermal heating under regular and 318 non-concentrated sunlight. Consequently, the $\mathrm{CaCl}_{2}$ in our hydrogel after drying process at $80{ }^{\circ} \mathrm{C}$ 319 was mainly a mixture of $\mathrm{CaCl}_{2} \cdot 4 \mathrm{H}_{2} \mathrm{O}$ and $\mathrm{CaCl}_{2} \cdot 2 \mathrm{H}_{2} \mathrm{O}$, which is confirmed by XRD analysis 320 (Figure S4) and phase diagram. ${ }^{47}$ Since $4 \mathrm{~g}$ of $\mathrm{CaCl}_{2}$ was loaded into $1 \mathrm{~g}$ of PAM-CNT (4/5 of 321 overall weight), the loading ratio of $\mathrm{CaCl}_{2}$ was $80 \%$. The overall weight change contributed by 322 hydration reaction should be insignificant during water sorption process, i.e. $<30 \%$, which is 
323 small portion of the final water sorption amount. This analysis indicates that most of the water

324 sorption for the hydrogel material is contributed by deliquesce of the $\mathrm{CaCl}_{2}$ aqueous solution.

325 The amount of water sorbed during deliquescent stage is highly dependent on humidity of the

326 surroundings. Therefore, the sorption continuously increases with the increase of humidity,

327 which gives $\mathrm{CaCl}_{2}$ a broad sorption window as shown in Figure 5 (a), (d), and (g).

328 Derivative weight change based on the results obtained from static RH test was employed to 329 investigate the water sorption kinetics of $\mathrm{CaCl}_{2}, \mathrm{PAM}-\mathrm{CaCl}_{2}$ and $\mathrm{PAM}-\mathrm{CNT}-\mathrm{CaCl}_{2}$ (Figure 5 (c), 330 (f) and (i)). All three samples show a small sorption rate at $\mathrm{RH} 10 \%$ (mixing ratio $2.0 \mathrm{~g} / \mathrm{kg}_{\text {air }}$ ) in 331 the first 200 mins, and the sorption rate quickly decreases to near zero after 200 min, implying a 332 small amount of water sorption behavior at $\mathrm{RH} 10 \%$. When $\mathrm{RH}$ is $>10 \%, \mathrm{PAM}-\mathrm{CaCl}_{2}$ and 333 PAM-CNT-CaCl 2 share similar sorption trends to that of $\mathrm{CaCl}_{2}$, but with much higher sorption 334 rates, which might be due to the porous structure of the hydrogels. During the period of the static $335 \mathrm{RH}$ test (i.e. $1000 \mathrm{~min}$ ), $\mathrm{PAM}-\mathrm{CaCl}_{2}$ and $\mathrm{PAM}-\mathrm{CNT}-\mathrm{CaCl}_{2}$ reached their saturation states at the 336 definite $\mathrm{RH}$ of 10,35 and $60 \%$, indicated by their sorption rate at the end of the test being quite 337 close to zero. However, at RH 35, 60 and $80 \%$, pristine $\mathrm{CaCl}_{2}$ salt failed to reach its saturation 338 state within $1000 \mathrm{~min}$, which might be attributed to its liquid characteristic after deliquescence. 339 Presumably, water sorption only occurs and is controlled by boundary layer at the air on the $340 \mathrm{CaCl}_{2}$ solution interface.

341 By comparing the results of three batches of the samples all together, the following conclusions 342 can be made: (1) the water sorption performance of $\mathrm{PAM}-\mathrm{CaCl}_{2}$ and $\mathrm{PAM}-\mathrm{CNT}-\mathrm{CaCl}_{2}$ are 343 mainly contributed by $\mathrm{CaCl}_{2}$; (2) the hydrogel substrate does not suppress the overall water 344 sorption performance; (3) the hydrogel platform not only provides physical stability of the AWG 345 but also enhances the water sorption kinetics, leading to a faster vapor sorption rate than pristine 
$\mathrm{CaCl}_{2}$ salt. It is worth mentioning that the final weight changes in Figure $4 \mathrm{~d}$ and $\mathrm{g}$ are the

347 integrated value of water vapor sorption throughout the whole RH ranges, which does not reflect

348 the sorption performance of the material at a specified RH condition. Our water sorption test

349 results was also compared with some of the other solid-state water sorbent (i.e. silica gel, zeolite,

350 MOF, activated alumina, clay, etc.), demonstrated a superior water capacity (Table S1).

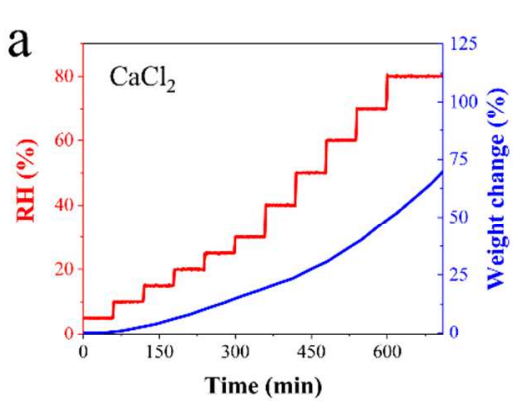

$\mathrm{b}$
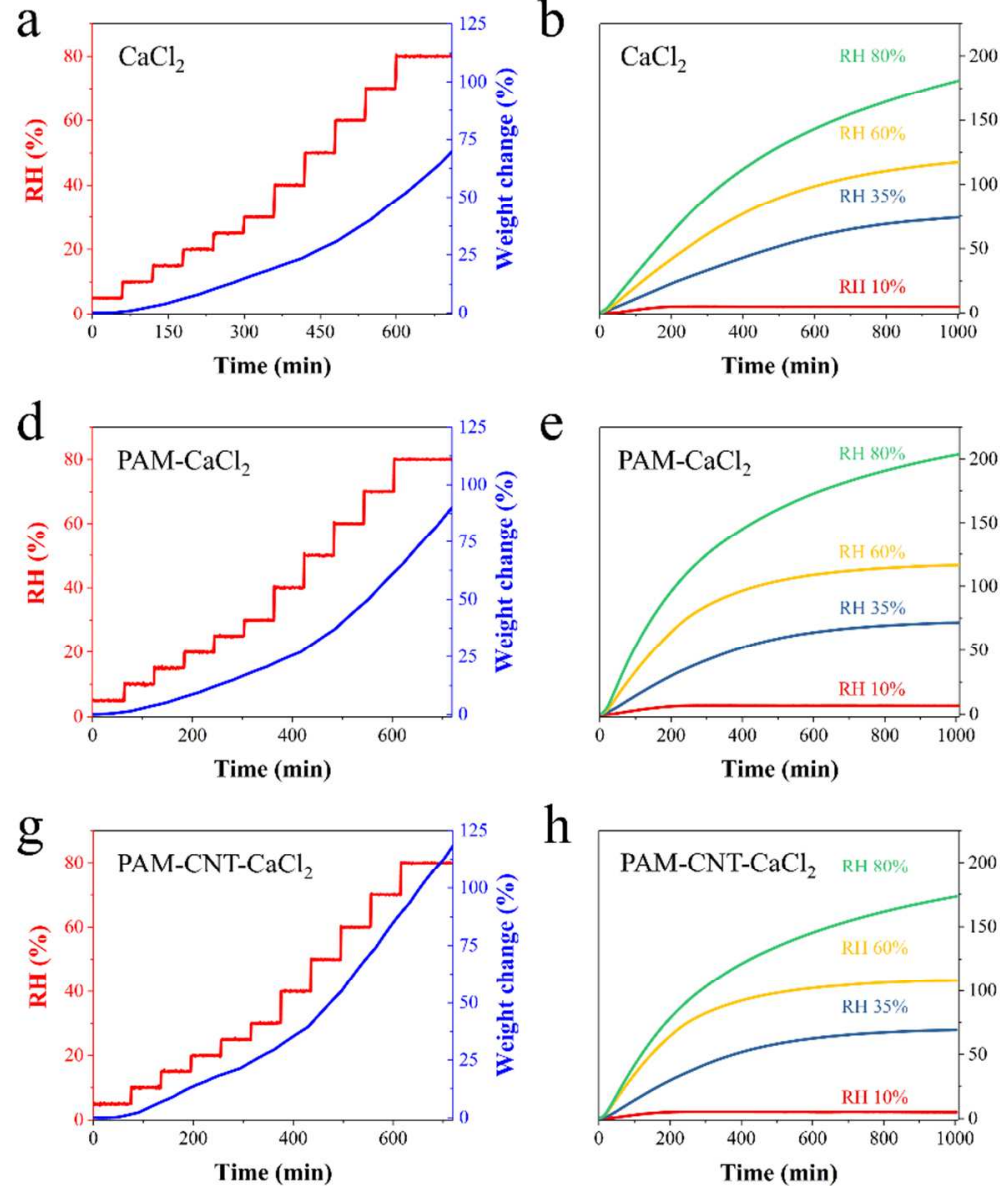

$\mathrm{e}$

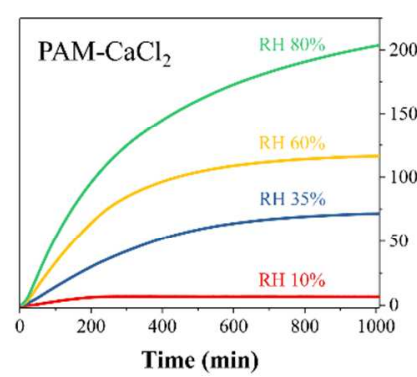

$\mathrm{h}$

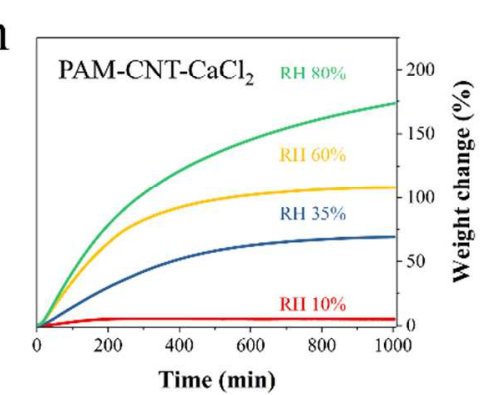

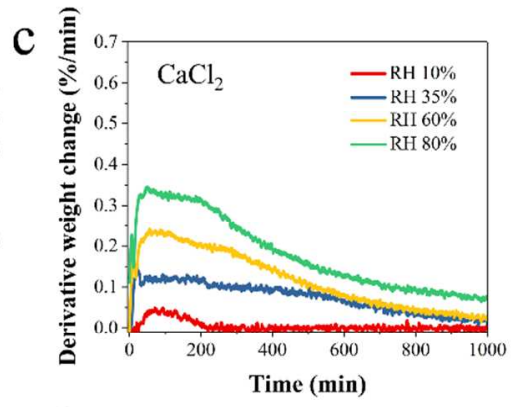
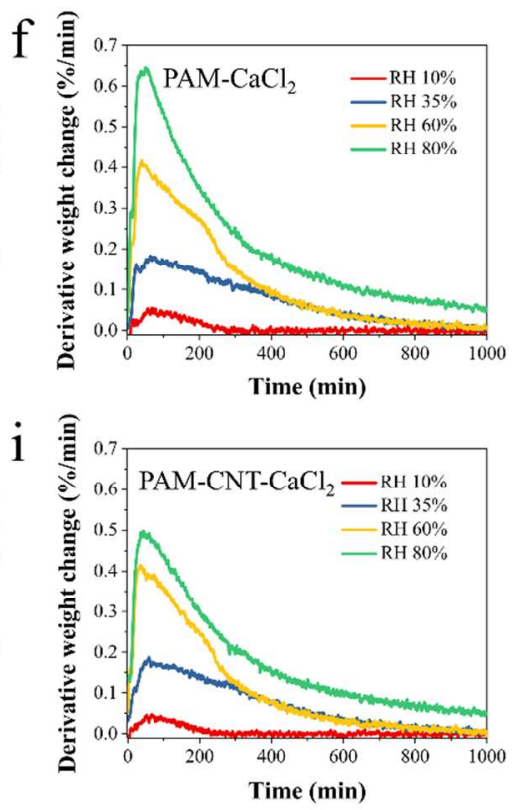

Figure 5. Water vapor sorption curves of (a), (b), (c) $\mathrm{CaCl}_{2}$, (d), (e), (f) $\mathrm{PAM}-\mathrm{CaCl}_{2}$, and (g), (h), sample weight before the sorption) 
357 In an AWG device, water is released under the help of sunlight via photothermal effect to 358 increase the temperature of the sorbent. ${ }^{16,19-20}$ In this work, the water release performance of the 359 hydrogels were investigated using a simulated sunlight source in lab. PAM-CaCl $\mathrm{C}_{2}$ and PAM$360 \mathrm{CNT}-\mathrm{CaCl}_{2}$ hydrogel samples were firstly stored at room temperature $\left(22{ }^{\circ} \mathrm{C}\right)$ in air with $\mathrm{RH} 60 \%$ 361 (mixing ratio $9.7 \mathrm{~g} / \mathrm{kg}_{\text {air }}$ ) for 36 hours to ensure a full water sorption. The water content of these 362 two water-saturated hydrogels were $53.7 \%$ for $\mathrm{PAM}-\mathrm{CaCl}_{2}$ and $54.5 \%$ for $\mathrm{PAM}-\mathrm{CNT}-\mathrm{CaCl}_{2}$ 363 hydrogel, respectively. $5.0 \mathrm{~g}$ of the water-saturated hydrogels were exposed under a simulated 364 sunlight with an intensity of $1 \mathrm{~kW} / \mathrm{m}^{2}$ for water releasing. The surface temperature of PAM$365 \mathrm{CaCl}_{2}$ only increased to $35{ }^{\circ} \mathrm{C}$ under the light illumination for 50 mins, and then slowly increased 366 to approximately $42{ }^{\circ} \mathrm{C}$ after 275 mins. The temperature increase is mainly attributed to the light

367 sorption by water in this case as discussed in Figure 3 (a). The surface temperature of the 368 hydrogel is determined by its energy balance. In the initial stage of 50 mins light illumination, 369 there is a relatively fast water release (Figure 6 (a)), which takes away a large amount of heat and 370 thus leads to a low temperature of the hydrogel. The water evaporation rate then gradually 371 decreases because the salt concentration in the residual water inside the hydrogel keeps 372 increasing during this process due to the loss of water. As a result, the heat consumption by the 373 water evaporation decreases, moving the balance to a higher equilibrium temperature. At the end 374 of the experiment, the temperature of the $\mathrm{PAM}-\mathrm{CaCl}_{2}$ reached $42{ }^{\circ} \mathrm{C}$ and $25 \%$ of the total weight 375 of the hydrogel was lost to the released water. This result suggests that only less than half of the 376 water inside the PAM- $\mathrm{CaCl}_{2}$ hydrogel was able to be released.

377 As to PAM-CNT-CaCl 2 , its surface temperature jumped to $50{ }^{\circ} \mathrm{C}$ initially at 25 mins, which is 15 $378{ }^{\circ} \mathrm{C}$ higher than that of $\mathrm{PAM}-\mathrm{CaCl}_{2}$. This comparison convincingly demonstrates the great 379 photothermal effect of the CNTs in the hydrogel. It should be noted that, due to its higher 
380 temperature, PAM-CNT-CaCl 2 had a much higher evaporation rate than $\mathrm{PAM}-\mathrm{CaCl}_{2}$. The water 381 evaporation rate then gradually decreased along with the increase of the surface temperature. The 382 temperature recorded in the end was $75{ }^{\circ} \mathrm{C}$ and the weight change $\%$ was $\sim 53 \%$ at the end of 270 383 min for PAM-CNT-CaCl 2 , indicating almost all $(>97 \%)$ sorbed water inside PAM-CNT-CaCl 2 384 was released. With most of the available water being released from the hydrogel, the heat loss 385 via convection, radiation and conduction are the major energy consumption to balance the 386 constant solar input, and therefore the hydrogel temperature profile shows a plateau in the last 387 stage from $180 \mathrm{~min}$ to $270 \mathrm{~min}$ as shown in Figure 6 (b).

388 Figures 5 (c) and (d) show the temperature and weigh variation time course of PAM-CNT-CaCl 2 389 irradiated with simulated sunlight with varied light intensity. The temperature observed at 270 390 min under $0.6,0.8$ and $1.0 \mathrm{~kW} / \mathrm{m}^{2}$ sunlight illumination was 55,66 and $75{ }^{\circ} \mathrm{C}$ (Figure 6 e1-e4), 391 respectively. The corresponding weight change of the samples were 44, 49 and 53\%, respectively, 392 corresponding to 80,89 and $97 \%$ release of the sorbed water. It demonstrates that most of the 393 sorbed water can still be efficiently released under weakened sunlight. These photothermal394 assisted water release experiments indicate that PAM-CNT-CaCl ${ }_{2}$ hydrogel has a great potential 395 as an efficient AWG working within wide range of $\mathrm{RH}$ and sunlight conditions. 

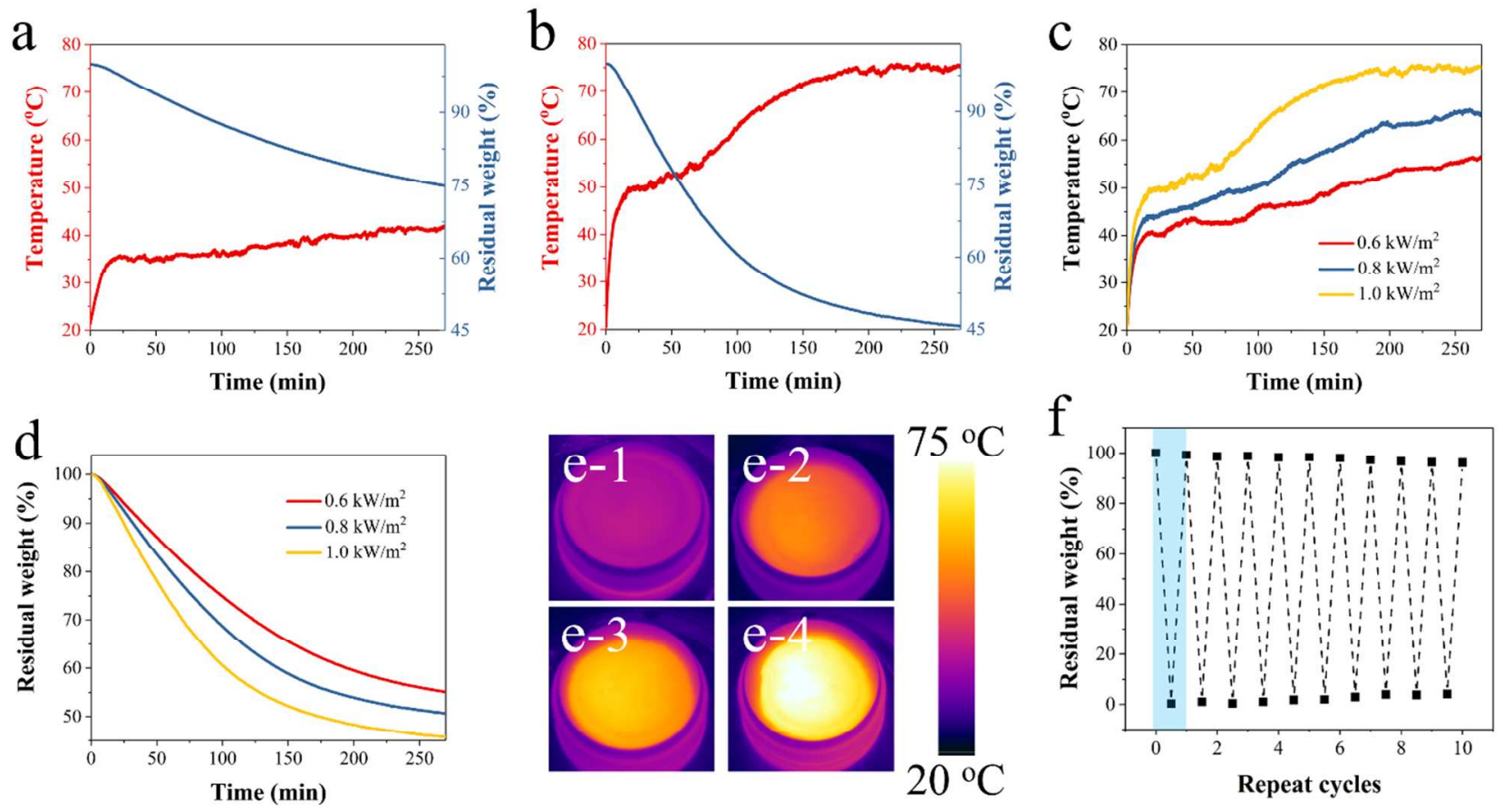

Figure 6. (a) Time course of temperature and weight change of (a) PAM-CaCl 2 , (b) PAM-CNT-

$\mathrm{CaCl}_{2}$ under $1 \mathrm{~kW} / \mathrm{m}^{2}$ light irradiation. (c) Temperature and (d) weight change profiles of PAM-

$399 \mathrm{CNT}-\mathrm{CaCl}_{2}$ irradiated under varied sunlight strength. (e) IR image of PAM-CaCl 2 under 1 $\mathrm{kW} / \mathrm{m}^{2}$ sunlight irradiation, $\mathrm{PAM}-\mathrm{CNT}-\mathrm{CaCl}_{2}$ under $0.6,0.8$ and $1 \mathrm{~kW} / \mathrm{m}^{2}$ irradiation, respectively. (f) Stability test of PAM-CNT-CaCl 2 . Blue shade highlights the first sorption-andrelease cycle and residual weight (\%) is relative to the total amount of the water sorbed by PAMCNT- $\mathrm{CaCl}_{2}$ during 36 hours saturation. performed. Water sorption was conducted by letting $2.5 \mathrm{~g}$ of the dried hydrogel sitting in an open air with $\mathrm{RH}$ of $60 \%$ at $22{ }^{\circ} \mathrm{C}$ for 36 hours in the dark, followed by one sun irradiation for 5 hours.

407 The whole cycle was repeated for 10 times and the results are presented in Figure 6 (f). As can 408 be seen, the water sorption and release performances of PAM-CNT- $\mathrm{CaCl}_{2}$ show no degradation 409 after 10 cycles, indicating its long-term operational stability. It has to be mentioned that instead 
410 of matching the time scheme of daily cycle (i.e. $24 \mathrm{~h}$ ), the cycling test was carried out based on

411 the time scheme of 36-hour sorption plus 5-hour desorption process, which can be treated as a

412 reference value to estimate the stability of PAM-CNT-CaCl2 AWG hydrogel.

413 Solar water collection devices.

414 "Easy-to-assemble-at-household" water collection device. In light of practical application, a

415 field test based on an "easy-to-assemble-at-household" water collection device was conducted. A

416 very simple but all in one device was fabricated by using easily available and cheap commercial

417 materials and used outdoors for field test. Figure 7 (a) illustrates the structure of this device,

418 consisting of (1) a plastic box as container, (2) metal foil as isolator (aluminum) and heat

419 conductive side wall (copper), (3) transparent cap and (4) PAM-CNT-CaCl 2 hydrogel. The

420 choice of the copper metal foil is because it possesses a high thermal conductivity and therefore

421 is beneficial to water condensation on this wall plate surface using the ambient air as the heat

422 sink. The driving force of the water condensation is the temperature gradient between the cold

423 copper surface of the container wall and the warm PAM hydrogel. The warm hydrogel produces

424 a water vapor with high partial pressure in the air inside the container, which is higher than the

425 saturated vapor pressure of water. When the vapor meets the cold wall, it condenses on the

426 surface of the cold wall, producing liquid water. Figure 7 (b) shows the digital photo of the

427 device.

428 A round-shaped dry hydrogel with a dry weight of $35 \mathrm{~g}$ was put inside the device and the device

429 was then placed outdoors overnight in KAUST campus at Thuwal, KSA (5 pm April 28 to 10 am 430 on April 29, 2018, with an average temperature of $26{ }^{\circ} \mathrm{C}$ and $60-70 \% \mathrm{RH}$, mixing ratio $12.6-14.3$

$431 \mathrm{~g} / \mathrm{kg}_{\mathrm{air}}$ ). The device sorbed $37 \mathrm{~g}$ water during the period of time. Figures $6(\mathrm{c})$ and (d) present the 432 dimensions of the water loaded hydrogel embedded in the water collection device. The water 
433 release and collection was conducted under natural sunlight without any concentration. The 434 experiment started at 13:20 pm local time $(\mathrm{GMT}+3)$ and within 2.5 hours, around $20 \mathrm{~g}$ of fresh 435 water was collected inside the container (Figure $7(\mathrm{e}-\mathrm{g})$ ). The weather data can be found in 436 Figure $7(\mathrm{~h})$. The fact that only $20 \mathrm{~g}$ of the fresh water was collected out of $37 \mathrm{~g}$ of the total water 437 vapor harvested can be explained as follows: (1) there was a significant amount of water droplets 438 sticking onto the container walls; (2) the water release in the device was inside a close chamber 439 where there was a higher temperature than the case of the water release in open air as presented 440 in Figure 6. The water releasing performance in the sealed chamber was reduced due to a much 441 higher water vapor partial pressure inside the sealed container. (3) The design of the simple 442 device by easily accessible cheap materials weighs the convenience over energy efficiency. Thus, 443 its energy efficiency was not optimized. Nevertheless, our outdoor experiments demonstrate the 444 efficacy of the easy-to-assemble devices and the choices of building materials for such devices 445 can be very diverse, including plastic wrap/bag, empty can, glass jar, etc.

446 We also compared our work with conventional direct-cooling process by using moist harvesting 447 index (MHI). MHI was first introduced by Gido et al in 2016, and it is used to estimate the 448 relationship between energy consumption and water production under varied ambient condition 449 in direct cooling process. ${ }^{49}$ The detailed calculation can be found in supporting information. 450 As the result, the MHI is only 0.16 for $\mathrm{RH} 35 \%, 25{ }^{\circ} \mathrm{C}$ condition, where the direct cooling 451 process is not preferred but PAM-CNT-CaCl 2 hydrogel can still preserve an acceptable water 452 production yield. For RH $60 \%, 26^{\circ} \mathrm{C}$, the $\mathrm{MHI}$ increased to 0.46 , where both direct-cooling 453 method and PAM-CNT-CaCl 2 hydrogel can be used as AWH technic. These index also reflected 454 and matched the simulation results reported by Gido et al on the lithium chloride-based 455 continuous AWH system. ${ }^{31}$ 


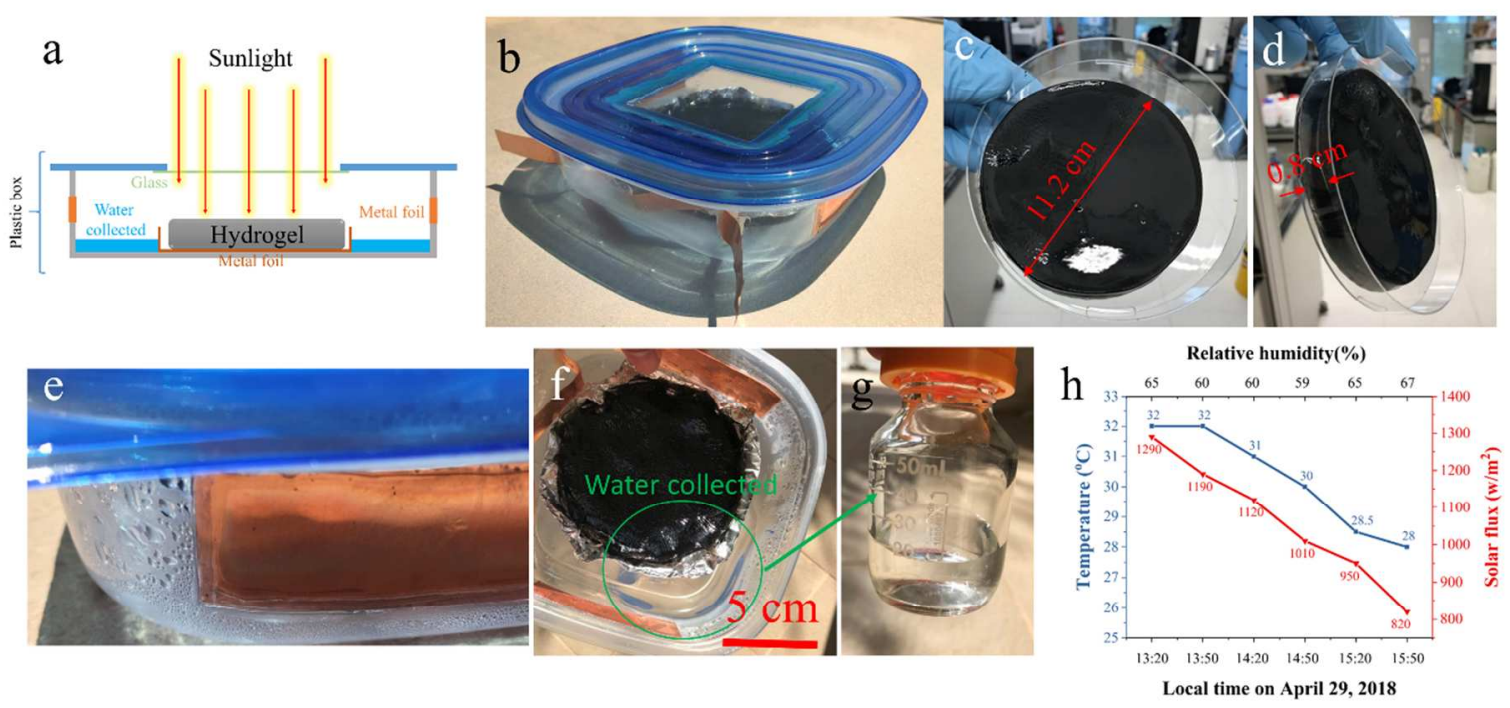

457 Figure 7. (a) Schematic and (b) digital photo of "easy-to-assemble-at-household" water 458 collection device prototype based on PAM-CNT-CaCl $\mathrm{C}_{2}$ hydrogel. (c) and (d) Dimension 459 illustration of PAM-CNT-CaCl 2 hydrogel used in this work. (e) Condensed water on the wall of 460 the box during water collection process. (f) Digital image of the hydrogel after water release

461 process. (g) Photo of water collected from (f). (h) Weather data during time period of the field test. The nature-sunlight-assisted work was conducted on April 29, 2018, KAUST, Thuwal, KSA.

463 To further enhance the performance of the device, one commercial magnifying glass was 464 combined with the previous device design, minor adjustment was carried out to install the 465 magnifying glass. In this test, $5 \mathrm{~g}$ of water loaded PAM-CNT-CaCl 2 hydrogel $(\sim 2.65 \mathrm{~g}$ of water 466 sorbed in the hydrogel) was placed into the modified device and irradiated by simulated sunlight.

467 Figure S5 shows the schematic (a) and digital image (b) of the water collection device with a 468 magnifying glass on top, where condensed water droplets can be clearly seen on the surface of its 469 copper side wall (Figure S5 b1 and b2) after $10 \mathrm{~min}$ and $60 \mathrm{~min}$. After 2 hours, $2.6 \mathrm{~g}$ of water 470 was collected, representing $98 \%$ of the pre-sorbed water. 
471 The device with the magnifying glass delivered more water (i.e. $0.52 \mathrm{~g}$ vs. $0.30 \mathrm{~g}$ water per gram

472 of the water loaded hydrogel) within a shorter period of time (i.e. 2.0 vs. 2.5 hours) than the one

473 without the glass. This result is expected and the magnifying glass concentrated the light, led to a

474 higher temperature of the hydrogel, and thus enhanced water release.

475 Both of the devices, namely with and without the magnifying glass, can be well suited for point-

476 of-use water production as emergency response or in case of natural disasters, wars, etc. In the

477 real-world applications, the overall performance for these water harvesting device may be

478 influence by several factors, such as daily variation in solar irradiation density, weather

479 conditions, etc. These aspects need be counted into consideration when deploying hydrogel. In

480 operating the device, simple maintenance (i.e. transparent cap cleaning/wiping) might be needed

481 from time to time. With some simplifying assumptions, the material cost of an easy-to-assemble

482 device which could deliver 3 liter per day, the minimum daily water requirement per capita, was

483 estimated to be $\$ 3.2$ and $\$ 1.76$ under RH 35\% and RH $60 \%$ weather conditions during water

484 vapor sorption, respectively (Table S2). This device is focused on providing clean water to fulfill

485 the minimum water intake requirement for individuals. The guideline value (i.e. 3 liters per day 486 per person) suggested by WHO was used to roughly estimate the overall investment cost. Even

487 though personal hygiene is highly important to lower down the public health risk, however, it is 488 beyond the scope of this work to provide water for wash purpose and thereafter the investments 489 are not included in the estimation. ${ }^{50}$

490 The quality of the produced water was examined by ICP-OES equipped with a segmented-array491 charge-coupled device (SCD) detector. Since the salt we used as sorbent in this work is $\mathrm{CaCl}_{2}$, 492 the concentration of calcium element was checked and found to be below the detect limit of ICP- 
493 OES-SCD (0.5-1 ppb), which makes it not a concern according to WHO water quality guide and

494 thus suitable for direct potable consumption. ${ }^{50}$

495 Thus the results in this work indicates that the hybrid PAM hydrogel possesses outstanding water 496 sorption capability which is similar to $\mathrm{CaCl}_{2}$, and its flexible solid form makes it an effective

497 AWG. The excellent water production performance of the hydrogel based simple and affordable

498 device was confirmed under field conditions. Given the fact that the working RH range of the 499 hybrid hydrogel covers most of arid deserts, almost all islands, and inland remote regions, the 500 AWG devices based on the hydrogel are low cost, versatile, deployable, and thus suitable for 501 delivering much needed fresh water therein.

\section{Associated content}

506 Supporting information

507 The supporting information is available free of charge on the ACS publication website. and PAM-CNT $\mathrm{CaCl}_{2}$ hydrogel, water sorption curves of PAM and PAM-CNT hydrogel, XRD

510 pattern, details of concentrated sunlight-assisted water collection devices. Calculation of

511 Moisture harvesting index (MHI). 


\section{Author information}

515 Corresponding Author

516 * peng.wang@kaust.edu.sa

517 Notes:

518 Peng Wang, Renyuan Li, Yusuf Shi and Mengchun Wu have a patent application related to the 519 work presented in this paper.

520 Acknowledgments

521 This work was supported by the King Abdullah University of Science and Technology (KAUST)

522 Center Competitive Fund (CCF) awarded to the Water Desalination and Reuse Center (WDRC).

523 


\section{References}

525 1. WWAP, The United Nations World Water Development Report 2015: Water for a

526 Sustainable World. Paries, UNESCO. 2015.

527 2. Li, R.; Zhang, L.; Wang, P., Rational Design of Nanomaterials for Water Treatment.

$528 \quad$ Nanoscale 2015, 7 (41), 17167-17194.

529 3. Schneider, S. H.; Root, T. L.; Mastrandrea, M. D., Encyclopedia of Climate and Weather, $530 \quad 2^{\text {nd }}$ edition; 2011, DOI:10.1093/acref/9780199765324.001.0001.

531 4. Kalmutzki, M. J.; Diercks, C. S.; Yaghi, O. M., Metal-Organic Frameworks for Water 532 Harvesting from Air. Adv. Mater. 2018, 1704304. DOI:10.1002/adma.201704304.

533 5. Mekonnen, M. M.; Hoekstra, A. Y., Four Billion People Facing Severe Water Scarcity. 534 Sci. Adv. 2016, 2 (2), e1500323.

535 6. Wang, P., Emerging Investigator Series: The Rise of Nano-Enabled Photothermal 536 Materials for Water Evaporation and Clean Water Production by Sunlight. Environ. Sci.: Nano $537 \mathbf{2 0 1 8}, 5,1078-1089$.

$538 \quad 7 . \quad$ Zhang, L.; Wu, J.; Hedhili, M. N.; Yang, X.; Wang, P., Inkjet Printing for Direct 539 Micropatterning of a Superhydrophobic Surface: Toward Biomimetic Fog Harvesting Surfaces. J.

540 Mater. Chem. A 2015, 3 (6), 2844-2852.

$541 \quad 8 . \quad$ Andrews, H. G.; Eccles, E. A.; Schofield, W. C. E.; Badyal, J. P. S., Three-Dimensional 542 Hierarchical Structures for Fog Harvesting. Langmuir 2011, 27 (7), 3798-3802.

$5439 . \quad$ Moyuan, C.; Jie, J.; Kan, L.; Shixue, D.; Kesong, L.; Lei, J., Facile and Large-Scale 544 Fabrication of a Cactus-Inspired Continuous Fog Collector. Adv. Funct. Mater. 2014, 24 (21), $545 \quad 3235-3240$. 
546 10. Ju, J.; Bai, H.; Zheng, Y.; Zhao, T.; Fang, R.; Jiang, L., A Multi-structural and Multi-

547 Functional Integrated Fog Collection System in Cactus. Nat. Commun. 2012, 3, 1247.

548 11. Estrela, M. J.; Valiente, J. A.; Corell, D.; Millán, M. M., Fog Collection in the Western

549 Mediterranean Basin (Valencia region, Spain). Atmos. Res. 2008, 87 (3), 324-337.

550 12. Olivier, J.; de Rautenbach, C. J., The Implementation of Fog Water Collection Systems in 551 South Africa. Atmos. Res. 2002, 64 (1), 227-238.

552 13. McHugh, T. A.; Morrissey, E. M.; Reed, S. C.; Hungate, B. A.; Schwartz, E., Water 553 From Air: An Overlooked Source of Moisture in Arid and Semiarid Regions. Sci. Rep. 2015, 5, 55413767.

555 14. Wikramanayake, E. D.; Ozkan, O.; Bahadur, V., Landfill Gas-Powered Atmospheric 556 Water Harvesting for Oilfield Operations in the United States. Energy 2017, 138, 647-658. 557 15. Wahlgren, R. V., Atmospheric Water Vapour Processor Designs for Potable Water 558 Production: A Review. Water Res. 2001, 35 (1), 1-22.

559 16. Kim, H.; Rao, S. R.; Kapustin, E. A.; Zhao, L.; Yang, S.; Yaghi, O. M.; Wang, E. N., 560 Adsorption-Based Atmospheric Water Harvesting Device for Arid Climates. Nat. Commun. 2018, $5619(1), 1191$.

562 17. Wang, J. Y.; Liu, J. Y.; Wang, R. Z.; Wang, L. W., Experimental Investigation on Two 563 Solar-Driven Sorption Based Devices to Extract Fresh Water From Atmosphere. Appl. Therm. $564 \quad$ Eng. 2017, 127, 1608-1616.

565 18. Ji, J. G.; Wang, R. Z.; Li, L. X., New Composite Adsorbent for Solar-driven Fresh Water 566 Production from The Atmosphere. Desalination 2007, 212 (1), 176-182. 
567 19. Kim, H.; Yang, S.; Rao, S. R.; Narayanan, S.; Kapustin, E. A.; Furukawa, H.; Umans, A.

568 S.; Yaghi, O. M.; Wang, E. N., Water Harvesting From Air With Metal-Organic Frameworks

569 Powered by Natural Sunlight. Science, 2017, eaam8743.

570 20. Li, R.; Shi, Y.; Shi, L.; Alsaedi, M.; Wang, P., Harvesting Water from Air: Using

571 Anhydrous Salt with Sunlight. Environ. Sci. Tech. 2018, 52 (9), 5398-5406.

572 21. Furukawa, H.; Gándara, F.; Zhang, Y.-B.; Jiang, J.; Queen, W. L.; Hudson, M. R.; Yaghi, 573 O. M., Water Adsorption in Porous Metal-Organic Frameworks and Related Materials. J. Am.

574 Chem. Soc. 2014, $136(11), 4369-4381$.

575 22. Canivet, J.; Fateeva, A.; Guo, Y.; Coasne, B.; Farrusseng, D., Water Adsorption in MOFs: 576 Fundamentals and Applications. Chem. Soc. Rev. 2014, 43 (16), 5594-5617.

577 23. Li, R.; Zhang, L.; Shi, L.; Wang, P., MXene $\mathrm{Ti}_{3} \mathrm{C}_{2}$ : An Effective 2D Light-to-Heat 578 Conversion Material. ACS Nano 2017, 11 (4), 3752-3759.

579 24. Shi, L.; Wang, Y.; Zhang, L.; Wang, P., Rational Design of A Bi-Layered Reduced 580 Graphene Oxide Film on Polystyrene Foam for Solar-Driven Interfacial Water Evaporation. $J$. 581 Mater. Chem. A 2017, 5 (31), 16212-16219.

582 25. Chua, H. T.; Ng, K. C.; Chakraborty, A.; Oo, N. M.; Othman, M. A., Adsorption 583 Characteristics of Silica Gel + Water Systems. J. Chem. Eng. Data 2002, 47 (5), 1177-1181.

584 26. Dzhigit, O. M.; Kiselev, A. V.; Mikos, K. N.; Muttik, G. G.; Rahmanova, T. A., Heats of 585 Adsorption of Water Vapour on X-Zeolites Containing $\mathrm{Li}^{+}, \mathrm{Na}^{+}, \mathrm{K}^{+}, \mathrm{Rb}^{+}$, and $\mathrm{Cs}^{+} \mathrm{Cations}^{\text {Trans. }}$ 586 the Faraday Soc. 1971, 67 (0), 458-467.

587 27. Desai, R.; Hussain, M.; Ruthven, D. M., Adsorption of Water Vapour on Activated 588 Alumina. I - Equilibrium Behaviour. Can. J. Chem. Eng. 1992, 70 (4), 699-706. 
589 28. Wang, Y.; LeVan, M. D., Adsorption Equilibrium of Carbon Dioxide and Water Vapor 590 on Zeolites 5A and 13X and Silica Gel: Pure Components. J. Chem. Eng. Data 2009, 54 (10), $591 \quad 2839-2844$.

592 29. Mauer, L. J.; Taylor, L. S., Water-Solids Interactions: Deliquescence. Annu. Rev. Food 593 Sci. Technol. 2010, 1 (1), 41-63.

594 30. Brien, F. E. M. O., The Control of Humidity by Saturated Salt Solutions. J. Sci. Instrum. $595 \quad \mathbf{1 9 4 8 ,} 25(3), 73$.

596 31. Gido, B., Friedler, E., Broday, M., D., Liquid-Desiccant Vapor Separation Reduces the 597 Energy Requirements of Atmpspheric Moisture Harvesting. Environ. Sci. Technol. 2016, 50, $598 \quad 8362-8367$.

599 32. Ahmed, E. M., Hydrogel: Preparation, Characterization, and Applications: A Review. J. 600 Adv. Res. 2015, $6(2), 105-121$.

601 33. Schexnailder, P.; Schmidt, G., Nanocomposite Polymer Hydrogels. Colloid polym. Sci. $602 \quad 2009,287(1), 1-11$.

603 34. Zhou, C.; Wu, Q.; Yue, Y.; Zhang, Q., Application of Rod-Shaped Cellulose 604 Nanocrystals in Polyacrylamide Hydrogels. J. Colloid Interface Sci. 2011, 353 (1), 116-123. 605 35. Zhao, F.; Zhou, X.; Shi, Y.; Qian, X.; Alexander, M.; Zhao, X.; Mendez, S.; Yang, R.; 606 Qu, L.; Yu, G., Highly Efficient Solar Vapour Generation via Hierarchically Nanostructured 607 Gels. Nat. Nanotechnol. 2018. DOI:10.1038/s41565-018-0097-z.

608 36. Chang, J.; Shi, Y.; Wu, M.; Li, R.; Shi, L.; Jin, Y.; Qing, W.; Tang, C.; Wang, P., Solar609 Assisted Fast Cleanup of Heavy Oil Spills Using A Photothermal Sponge. J. Mater. Chem. A $610 \mathbf{2 0 1 8}, 6,9192-9199$. 
611 37. Wang, Y.; Zhang, L.; Wang, P., Self-Floating Carbon Nanotube Membrane on

612 Macroporous Silica Substrate for Highly Efficient Solar-Driven Interfacial Water Evaporation.

613 ACS Sustain. Chem. Eng. 2016, 4 (3), 1223-1230.

614 38. Orakdogen, N.; Okay, O., Correlation Between Crosslinking Efficiency and Spatial

615 Inhomogeneity in Poly(acrylamide) Hydrogels. Polym. Bull. 2006, 57 (5), 631-641.

616 39. Curcio, J. A.; Petty, C. C., The Near Infrared Absorption Spectrum of Liquid Water. $J$.

617 Opt. Soc. Am. 1951, 41 (5), 302-304.

618 40. Pope, R. M.; Fry, E. S., Absorption Spectrum (380-700 nm) of Pure water. II. Integrating

619 Cavity Measurements. Appl. Opt. 1997, 36 (33), 8710-8723.

620 41. Panagiotopoulos, N. T.; Diamanti, E. K.; Koutsokeras, L. E.; Baikousi, M.; Kordatos, E.;

621 Matikas, T. E.; Gournis, D.; Patsalas, P., Nanocomposite Catalysts Producing Durable, Super-

622 Black Carbon Nanotube Systems: Applications in Solar Thermal Harvesting. ACS Nano 2012, 6

$623(12), 10475-10485$.

624 42. Yang, Z.-P.; Ci, L.; Bur, J. A.; Lin, S.-Y.; Ajayan, P. M., Experimental Observation of 625 An Extremely Dark Material Made By A Low-Density Nanotube Array. Nano Lett. 2008, 8 (2), $626 \quad 446-451$.

627 43. D., L. Y.; Irina, P.; Benjamin, F.; Ory, R.; Yachin, C.; Uri, C.; Shimon, M., Interactions 628 Between Inorganic Salts and Polyacrylamide in Aqueous Solutions and Gels. J. Polym. Sci. B: 629 Polym. Phys. 2003, 41 (5), 508-519.

630 44. Deng, Y.; Dixon, J. B.; White, G. N.; Loeppert, R. H.; Juo, A. S. R., Bonding Between 631 Polyacrylamide and Smectite. Colloids Surf. A: Physicochem. Eng. Asp. 2006, 281 (1), 82-91. 
632 45. Bowman, D. C.; Evans, R. Y.; Paul, J. L., Fertilizer Salts Reduce Hydration of 633 Polyacrylamide Gels and Affect Physical Properties of Gel-Amended Container Media. J. Am.

634 Soc. Hortic. Sci. 1990, 115 (3), 382-386.

635 46. V, K. V.; A, M. G.; S, N. Z.; V, D. A., pH and Salt Effects on Interpolymer

636 Complexation via Hydrogen Bonding in Aqueous Solutions. Polym. Int. 2004, 53 (9), 1382-1387.

637 47. Baumgartner, M.; Bakker, R. J., $\mathrm{CaCl}_{2}-\mathrm{Hydrate}$ Nucleation in Synthetic Fluid Inclusions.

638 Chem. Geol. 2009, 265 (3), 335-344.

639 48. Ushak, S.; Suárez, M.; Véliz, S.; Fernández, A. G.; Flores, E.; Galleguillos, H. R., 640 Characterization of Calcium Chloride Tetrahydrate as A Phase Change Material and 641 Thermodynamic Analysis of the Results. Renew. Energy 2016, 95, 213-224.

642 49. Gido, B., Friedler, E., Broday, M., D., Assessment of Atmospheric Moisture Harvesting 643 by Direct Cooling. Atmos. Res. 2016, 182, 156-162.

644 50. WHO, Guidelines for Drinking-water Quality, $4^{\text {th }}$ edition. 2017 